pathologists have experience of unexpectedly low carboxyhaemoglobin saturation levels in fatal carbon-monoxide poisoning. The textbooks give $60 \%$ as the minimum lethal concentration for healthy subjects. Why then should apparently fit persons, below the age of 70 , die with saturation levels below $50 \%$ ? A series of 300 included 24 such cases, with values from 40 to $49 \%$ (palladium chloride analysis accurate to about $5 \%$ ).

An explanation was provided by two cases in which subclavian blood gave unbelievably low readings, but femoral samples showed higher saturation levels. Vigorous artificial respiration had been given to both. An infant from a fire was also given intravenous saline at hospital where artificial respiration was continued for an hour. Subclavian blood showed only $15 \%$ saturation and femoral blood $31 \%$, though hypostasis was characteristically pink. In a male suicide of 57 the values were 32 to $52 \%$, respectively.

Enquiries revealed that the local ambulance services give artificial respiration, with oxygen or Entonox, to all persons found dead, unless obviously inappropriate.

Since blood with a high carboxyhaemoglobin content does not clot, vigorous artificial respiration moves blood into and out of the lungs of the cadaver. Dissociation of carboxyhaemoglobin occurs, assisted by high oxygen concentrations in the respired gas. Some mixing of the blood in veins near the lungs results, lowering their carboxyhaemoglobin content. Femoral blood from the thigh is much less affected. Circulation of the infant's blood was probably assisted by the intravenous infusion and by the prolongation of artificial respiration.

When artificial respiration has been tried, carboxyhaemoglobin saturation levels will be falsely low in blood from sites near the lungs (heart, subclavian vein). Blood for analysis should be taken from more distant sites such as the thigh.

\section{Cryofibrinogenaemia and Activation of the Coagulation/Lysis Systems in Accidental Hypothermia of the Elderly}

H. B. GOODALL, A. S. TODD, D. MAClEAN, R. HENDERSON, AND J. F. KING (Department of Pathology, Ninewells Hospital, Dundee) This work investigates the paradox of ischaemic lesions in hypothermia despite reduced demands for oxygen when tissues are cooled. Tests for cold-precipitable proteins (cryoproteins) and activation of coagulation/fibrinolysis systems were made in 33 elderly patients with accidental hypothermia.

Cryofibrinogen precipitates in plasma when cooled, redissolves on warming, and is thereafter clottable with thrombin, but a simple screening procedure is to separate heparinized plasma at $37^{\circ} \mathrm{C}$, chill in a Wintrobe tube at $4^{\circ} \mathrm{C}$ for 48 hours, spin at $3000 \mathrm{rev} / \mathrm{min}$ for 30 minutes, and read the percentage of precipitate - the plasma (or heparin) cryocrit. Of the 33 hypothermic patients, 15 were in the normal range (up to $1.5 \%$ ), 5 equivocal $(1.5$ to $2.0 \%$ ), and 13 raised (over $2.0 \%$ ). Serum cryocrits, reflecting cryoglobulin, were all normal; thus raised plasma cryocrits indicate excess cryofibrinogen. The cryofibrinogen level appears to be related to prognosis. Only 1 of 20 patients with normal or equivocal levels died before normal temperature was restored, but 6 of 13 patients with raised plasma cryocrit died hypothermic. The mean plasma cryocrit for those surviving hypothermia $(2.8 \%)$ is significantly lower than for those dying hypothermic $(9.9 \%)$ $\mathrm{P}<0.025$. The long-term overall mortality is $30 \%$ with normal cryocrit, $40 \%$ with equivocal cryocrit, and $62 \%$ with raised cryocrit. These findings are probably related to serious underlying disorders, especially infections. Hyperviscosity from gelling of cryofibrinogen at low temperature may impair the microcirculation. In addition, many patients show evidence of activation of the coagulation/lysis systems. Damage to vascular endothelium may play a part in this complex process.

\section{Molecular Weight Markers for Poly- acrylamide Gel Electrophoresis}

J. T. WHICHER AND D. BAREFORD (Department of Chemical Pathology, Bristol Royal Infirmary) Sodium dodecyl sulphate (SDS) polyacrylamide gel electrophoresis is a method widely used for determining the molecular weight of proteins. When a protein combines with SDS, a negatively charged micelle is formed, the electrophoretic mobility of which on polyacrylamide gel depends entirely upon the molecular size of the protein.

This method of separating proteins according to their molecular weight has been useful in determining whether proteinuria is glomerular, tubular or due to Bence Jones protein.

The successful use of the method depends on the availability of suitabl倍 purified proteins of known molecula? weight to act as markers.

A method is described of preparing proteins with a known molecular weigk for use as markers in this electrophoretio system. Polymers of light chains extracte $\overline{\bar{\phi}}$ from the urine of myeloma patients were prepared by forming peptide bonds using carbodiimides. The polymers spanning molecular weight range $22500-11250$ षे are stable in pH 5.0 buffer for several months at $4{ }^{\circ} \mathrm{C}$ and may also be stored্ deep frozen. The advantage of such $\frac{9}{2}$ molecular weight marker is that obviates the need for a number of purifie proteins of different molecular weighpo The starting material is widely availabe and the polymers are easily made and store well.

\section{Leucocyte Enzyme Assay as a Means Diagnosis}

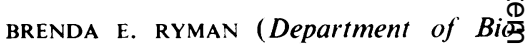
chemistry, Charing Cross Hospitg Medical School, London W6 8RF) In the last 20 years the use of leucocyte enzfnco assay to aid diagnosis has becing increasingly important. Possibly the getatest disadvantage of this technique is tha@ as yet, it does not form part of the norms armamentarium of hospital laboratorie Various methods of isolating leucocyt are available; it will be appreciate $\$$ however, that different methods git preparations containing varying pre portions of the individual cells that make up the so-called 'white cell' population such considerations may influence the quantitative results obtained.

In the field of the hereditary metabo ic diseases the use of leucocytes in son cases obviates the need for surgiç, biopsies under anaesthesia. It mus, however, be stressed that in certa genetic disorders such white cell studis are not diagnostically useful and, in fagt may give controversial results. Several groups of genetically inherited disorders are amenable to diagnosis via the use of employing leucocytes, and these include some of the disorders associated wif amino acid metabolism (eg, maple syrop urine diseases, hypervalinaemia, arginingsuccinic aciduria), carbohydrate metabdism ( $\mathrm{eg}$, galactosaemia, glycogen storafe diseases types II, III, IV, and VI, fructose 1,6-diphosphatase deficiency, manno sidosis, fucosidosis) and lipid metaboliş (Gaucher's, Niemann Pick's, Tay Sachत्ष, 